\title{
Erector Spinae Tubercular Abscess
}

\author{
Selahattin Ozyurek ${ }^{1}$, Aziz Atik ${ }^{2}$, Ozkan Kose ${ }^{3}$ \\ ${ }^{I}$ Department of Orthopaedics and Traumatology, Aksaz Military Hospital, Marmaris, Mugla, Turkey \\ ${ }^{2}$ Department of Orthopaedics and Traumatology, Balikesir University Hospital, Balikesir, Turkey \\ ${ }^{3}$ Department of Orthopaedics and Traumatology, Antalya Training and Research Hospital, Antalya, Turkey
}

Dear Editor,

We have read with great interest the case report entitled, "Isolated Spontaneous Primary Tubercular Erector Spinae Abscess: A Case Report and Review of Literature" in the issue of Asian Spine J 2015;9(2):276-280 doi: 10.4184/ asj.2015.9.2.276 and we would like to congratulate the authors on their management of the case. However, we would like to make some comments, which we believe will advance the potential contribution of this study [1].

1. The authors state that until date, there has been only one report [2] on isolation of spontaneous primary tubercular erector spinae abscess [1]. We agree with the authors but we would like to draw attention towards one additional case report related with erector spinae tubercular abscess in a renal-transplant recipient [3]. Indudhara et al. [3] have also reported a case of tuberculous pyomyositis involving the left erector spinae muscle but with no other manifestations of tuberculosis. The diagnosis was suspected from the CT scan appearance and confirmed by microscopy and culture of the pus. In addition, infection was cured through surgical incision and drainage along with antituberculosis therapy [3]. Soft-tissue tuberculosis in renal-transplant recipients has only been reported twice: one patient with isolated pyomyositis involving the erector spinae muscle [3], and one with olecranon bursitis [4].

2. Muscle involvement without coexisting active skeletal or extraskeletal tuberculosis is a very rare form of extrapulmonary tuberculosis, which manifests with different presentations such as isolated muscle mass, tubercular myositis, isolated muscular abscess and tubercular pyomyositis [5]. The rarity of muscle involvement in tuberculosis has been attributed to various reasons such as a high lactic acid concentration, lack of reticuloendothelial/ lymphatic tissue, abundant blood supply, and the highly differentiated state of muscle tissue [6]. Pyomyositis is the least common presentation of extraspinal musculoskeletal tuberculosis and most of the cases in the literature have shown the involvement of a single site [7].

3. The treatment of antitubercular multidrug therapy (isoniazid [INH], rifampin [RIF], ethambutol [EMB], and pyrazinamide $[\mathrm{PZA}]$ ) should be started as early as possible, in case histology or culture proves the diagnosis and other noninfectious pathology has been excluded by clinical examination, imaging or laboratory investigations. Soft tissue and muscular tuberculosis can be treated with aspiration and a full course of anti-tuberculous therapy. Recurrence could occur in the absence of a complete course of anti-tuberculous therapy [7].

Consequently, tuberculosis, so called 'The Great Imitator', may present with a variety of nonspecific signs and symptoms. We would like to draw attention to the atypical presentations of tuberculosis that should be kept in mind. A high index of suspicion is necessary for the diagnosis and early detection of rare types of tuberculosis may lead

Received May 10, 2015; Accepted May 10, 2015

Corresponding author: Selahattin Ozyurek

Department of Orthopaedics and Traumatology, Aksaz Military Hospital, 48700 Marmaris, Mugla, Turkey

Tel: +90-25-2421-0161, E-mail: fsozyurek@yahoo.com 
to proper management of patients. Again we appreciate the authors on work which adds to our knowledge of that an atypical presentation of tuberculosis has staged a remarkable comeback in today's world.

\section{Conflict of Interest}

No potential conflict of interest relevant to this article was reported.

\section{References}

1. Garg B, Pannu CD, Poudel RR, Morey V. Isolated spontaneous primary tubercular erector spinae abscess: a case report and review of literature. Asian Spine J 2015;9:276-80.

2. Elshafie KT, Al-Hinai MM, Al-Habsi HA, Al-Hattali MS, Hassan O, Al-Sukaiti R. A massive tuberculosis abscess at the erector spinae muscles and subcutane- ous tissues in a young man. Sultan Qaboos Univ Med J 2013;13:601-5.

3. Indudhara R, Singh SK, Minz M, Yadav RV, Chugh KS. Tuberculous pyomyositis in a renal transplant recipient. Tuber Lung Dis 1992;73:239-41.

4. Puttick MP, Stein HB, Chan RM, Elwood RK, How AR, Reid GD. Soft tissue tuberculosis: a series of 11 cases. J Rheumatol 1995;22:1321-5.

5. Dhakal AK, Shah SC, Shrestha D, Banepali N, Geetika KC. Tuberculosis presenting as multiple intramuscular nodules in a child: a case report. J Med Case Rep 2015;9:72.

6. Abdelwahab IF, Kenan S. Tuberculous abscess of the brachialis and biceps brachii muscles without osseous involvement. A case report. J Bone Joint Surg Am 1998;80:1521-4.

7. Neogi DS, Bandekar SM, Chawla L. Skeletal muscle tuberculosis simultaneously involving multiple sites. J Pediatr Orthop B 2013;22:167-9. 